Acta Geod. Geoph. Hung., Vol. 38(3), pp. 363-374 (2003)

\title{
EVIDENCE ON TRIGGERED SEISMICITY ASSOCIATED WITH THE OCTOBER 20, 1991 UTTARKASHI EARTHQUAKE (GARHWAL HIMALAYA)
}

\author{
D Shanker ${ }^{1}$, Nipun KAPUR ${ }^{2}$, V P Singh ${ }^{3}$
}

[Manuscript received June 26, 2002]

\begin{abstract}
Two swarms of small earthquakes occurred on 22-24 October, 1995 and 13-18 September, 1996 about $15 \mathrm{~km}$ to the West-South-West (WSW) of the $1991 \mathrm{Ut}$ tarkashi earthquake $\left(m_{b}=6.6\right)$ in Himalayas. The later swarm has migrated $5 \mathrm{~km}$ to the WSW of the former. Analyses of their seismicity rates, width of apertures and migration rates show that these swarms are triggered by a disturbance caused by the occurrence of the Uttarkashi earthquake thus triggered by this event. The disturbance, having slow propagation, rate represents evidence of creep of the earth material transferring stresses to the WSW direction. Occurrence of creep (stableslip) motion is supported by the inferred south-west (SW) orientation of compressive stresses in Uttarkashi earthquake and presence of the north-west (NW) trending shear zones in the region. Ongoing convergence between India and Tibet would have provided the necessary tectonic forces transverse to the NW-SE trend of the Garhwal Himalayas indicating the future seismic activity of the region.
\end{abstract}

Keywords: Garahwal Himalayas; seismicity migration; triggered swarms

\section{Introduction}

Thrust faulting earthquakes pose substantial seismic hazard in many parts of the world including Himalaya. The seismicity of the Himalaya is ascribed to the convergence of Indian and Eurasian lithospheric plates, producing several prominent tectonic features in the area. Namely, the Main Boundary Thrust (MBT) and the Main Central Thrust (MCT) had evolved throughout the entire length of the Himalaya. The Garhwal Himalaya constitutes the northwestern part of the Himalaya where a seismic gap was identified (Khattri and Tyagi 1983) between the 1905 Kangra $(M=8.5)$ and 1934 Bihar $(M=8.4)$ great earthquakes.

With the onset of local seismicity monitoring in the Garhwal Himalaya (Wason et al. 1994, Kumar et al. 1998), a detailed seismicity picture of the region has started emerging. The 1991 Uttarkashi earthquake $(M=6.6)$ seismic sequence that recorded by a local network was studied in detail since foreshocks and aftershocks focal parameters were precisely determined (Kayal 1996). The observation and precise recording of both 1995 and 1996 swarms (Kumar et al. 1998) in close

\footnotetext{
${ }^{1}$ Department of Earthquake Engineering, Indian Institute of Technology Roorkee (formerly University of Roorkee), Roorkee-247667, UP, India, E-mail: dayasfeq@iitr.ernet.in

${ }^{2}$ GE Capital International Services, GE Employers Reinsurance Corporation-ACOE, Banalore560001, India, E-mail:Nipun.kapurn@geind.ge.com

${ }^{3}$ Department of Geophysics, Banaras Hindu University, Varanasi-221005, UP, India
} 
proximity to each other and to the epicenter of Uttarkashi earthquake in Himalayas, provides unique opportunity to study the possible effect of the Uttarkashi event on the seismicity of the region. A question arises on, what is the exact process leading to this effect. Is the stress changes caused by the coseismic slip during Uttarkashi earthquake or the post seismic slip on the fault plane or some other process that triggered these two swarms? In the present article, the possible explanation of the above question and as well as the pattern of the impending seismic activity in the area considered have been discussed.

\section{Location and tectonic setting of the region}

The study area is in a part western of the Himalayas known as Garhwal Himalaya (Fig. 1). From south to north the Himalayas are divided into the Sub-Himalaya, the Lesser Himalaya and the Higher Himalaya. The boundary between the SubHimalaya and Lesser Himalaya is marked by MBT, whereas the Lesser Himalaya separated from the Higher Himalaya by MCT. The major tectonic discontinuity, the MCT, is the predominant factor for major tectonic activity in the region. Geomorphologically, the area is characterized by a high-amplitude topography and great denudational slope. Three major rivers, Yamuna, Bhagirathi and Alsknanda (Fig. 1) drain it. The Yamuna and Bhagirathi flow transversely to the structural trend in beautiful channels. However, some tributaries are tectonically and structurally controlled. This area was hit by a severe $(\mathrm{M}=6.6)$ earthquake in October 1991. Its epicenter was near the town of Uttarkashi, located south of the surface trace of the northerly dipping MCT. The area has been strongly affected by tectonic movements, resulted to the development of innumerable folds, faults and weak planes in the region.

\section{Observational data}

In order to monitor the local seismicity in the considered region, a seismological network comprising of seven remote seismological stations, namely, Ayarchali (AYR), Chanderbadni (CHN), Dhaneti (DNT), Dhargaon (DHR), New Terhi Town (NTT), Srikot (SRT) and Surkanda (SUR) have been deployed by the Department of Earthquake Engineering, Indian Institute of Technology Roorkee (Fig. 2).

The data used for the analysis consist of two earthquake swarms, recorded by a network of seven stations continuously operating since Sep. 1993 (Kumar et al. 1998). The first swarm occurred during October 22-24, 1995, and lasted for a period of about $45 \mathrm{hrs}$ in which more than 150 events were recorded in the magnitude range of $-1 \leq M_{L} \leq 3.64$. The second swarm, located roughly to the west south west of the first, and occurred between September 13-18, 1996. This spurt in seismic activity was recorded for a period of $104 \mathrm{hrs}$ and $46 \mathrm{~min}$ during which more than 290 events were recorded in the magnitude range of $-1 \leq M_{L} \leq 4.67$.

The hypocentral location of the events of both swarms have been determined by the use of both $\mathrm{P}$ and $\mathrm{S}$ arrival times and a velocity model given by Chander et al. (1986). Since the closest station was located $19 \mathrm{~km}$, limited phase data were 


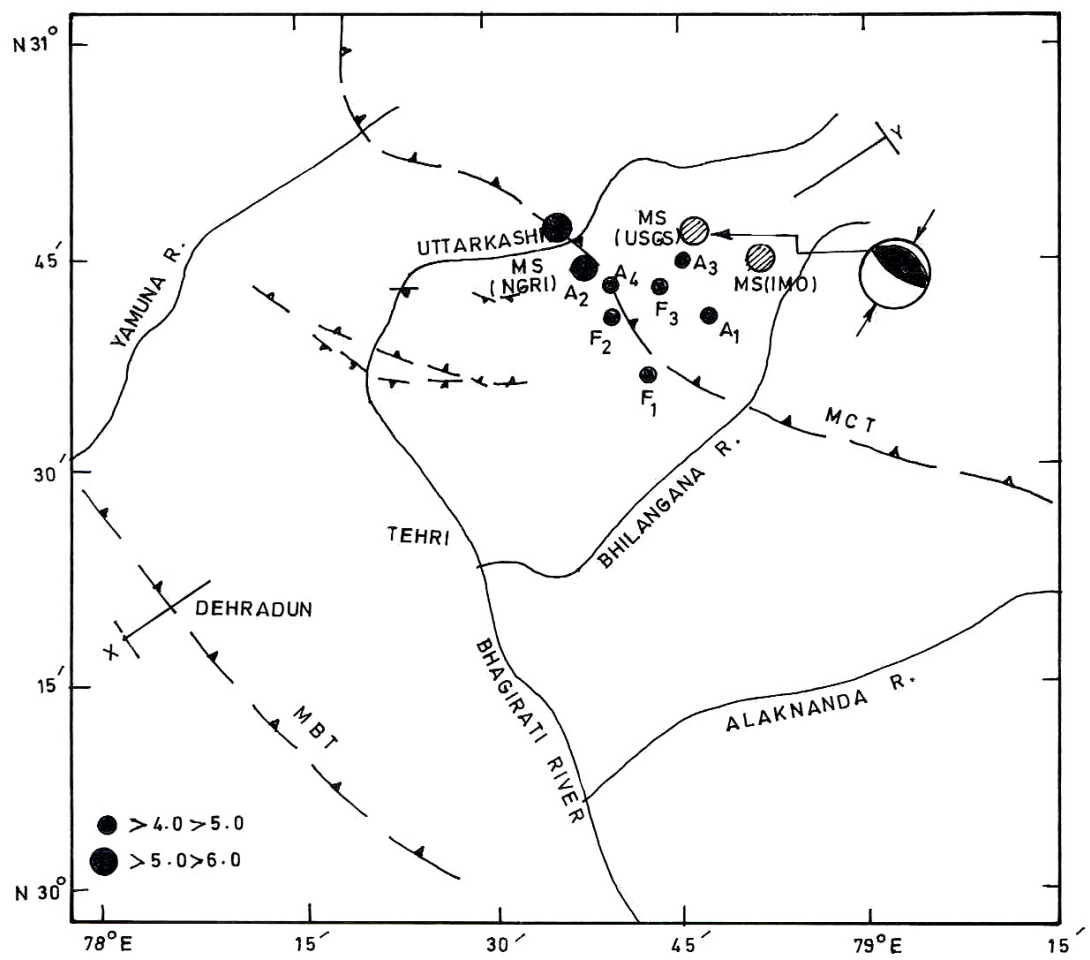

Fig. 1. Tectonic setting in Garhwal Himalaya and clustering of largest foreshocks F1, F2, F3 and largest aftershocks A1, A2, A3, A4 of the Uttarkashi earthquake. Large circles show the mainshock (M S) epicenters located by the IMD, USGS and NGRI. Focal mechanism of the mainshock is represented as a lower hemisphere projection. The small arrows indicate the direction of compressional stress axis as determined from the fault plane solution (Kayal 1996)

available and S-phase identification was not feasible for several events, which either was located with large standard errors. Therefore, the epicenters of events which primarily fulfill the criteria of having standard errors of RMS $\leq 0.50 \mathrm{~s} ; \mathrm{ERH}$ and ERZ $\leq 5.0 \mathrm{~km}$ have been considered for the analysis. Epicenters of 23 events of the 1995 swarm and 65 events of the 1996 swarm belong to this category. The epicentral locations of these 88 events are shown in Fig. 3a. We have also studied plots, which include events having larger errors in ERH and ERZ to check if the inferences drawn from the data set of 88 events remain unchanged. Two such plots consisting of 110 events with ERH, ERZ $\leq 7.5 \mathrm{~km}$ and 126 events with ERH, ERZ $\leq 10 \mathrm{~km}$ are shown in Fig. 3b and 3c, respectively. 


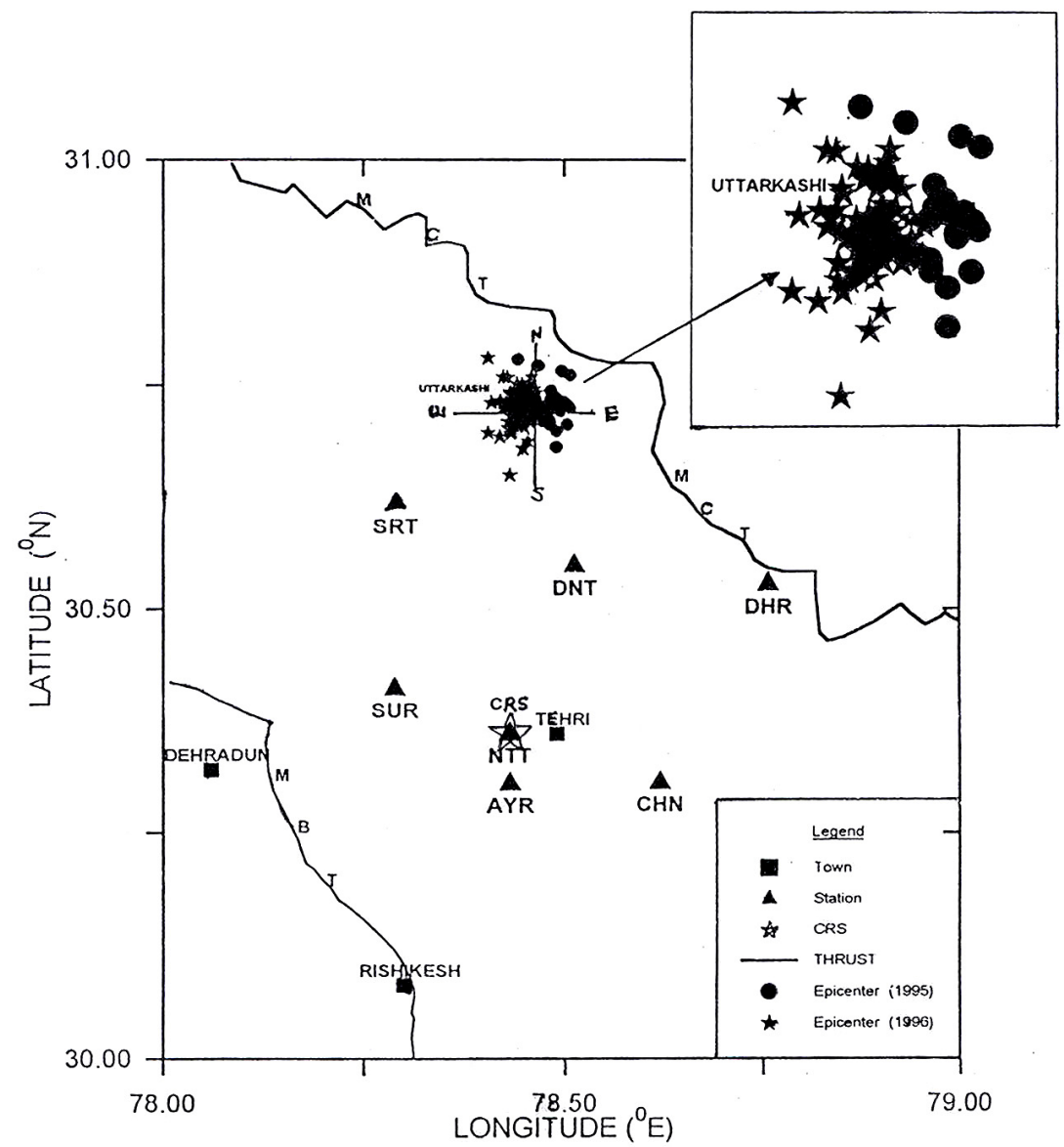

Fig. 2. Location map and tectonic features of the study region. Seismological network and epicentral locations of the events occurred during October and September 1996 swarms are also shown (Kumar et al. 1998)

\section{Data analysis and results}

The seismicity rates for the 1995 and 1996 swarms are $\sim 80$ events per day and $\sim 66$ events per day respectively. These values suggest that seismic activity decreased westward. Generally, an increase in seismic activity has been observed in the region of elevated stresses (Harris 1998). Thus, it is expected that stress enhancement took place in this region resulted in the two swarms. As the seismic activity decreased westward, the origin of the disturbance resulting in increased stresses would have been towards the east of these swarms.

A visual inspection of the two swarms in map view (Fig. 3) and their vertical cross sections of the seismic activity for the two sets of events have been drawn along N-S and E-W directions (Figs 4 and 5), respectively. These show an increase in aperture (largest distance between events at the extreme ends of the swarm) from 

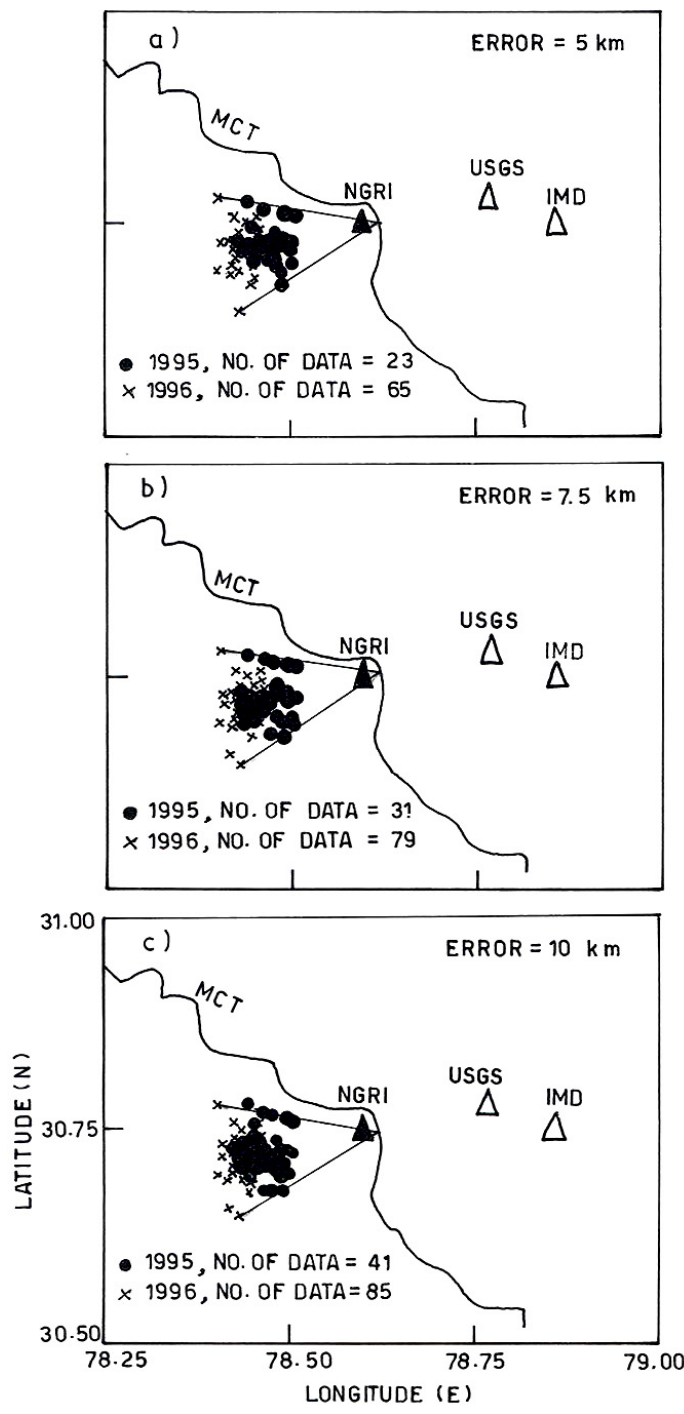

Fig. 3. Epicentral locations of (i) the Uttarkashi earthquake as given by NGRI, USGS and IMD and (ii) the two swarms of $1995(\bullet)$ and $1996(\mathrm{x})$ for three sets of events with $5 \mathrm{~km}, 7.5 \mathrm{~km}$ and $10 \mathrm{~km}$ error bars $(\mathrm{ER})$ in their horizontal $(\mathrm{H})$ and vertical $(\mathrm{Z})$ locations. The projections of the apertures of the two swarms to a point fall close to the epicenter of the Uttarkashi earthquake, as determined by NGRI

1995 to 1996 seismic activities. The distance between 1995 and 1996 swarms is 5 $\mathrm{km}$. In other words, one can say that horizontal migration rate of swarm (HMR) is $5 \mathrm{~km}$ per year. Also the radial velocity, i.e. radial migration rate (RMR), of swarm equal to $3.54 \mathrm{~km} / \mathrm{yr}$ (Fig. 6). If one assumes this rate and the time elapsed since the 1991 Uttarkashi earthquake, it can be inferred that the migration started at this strong event focus. Since the two swarms are overlapping and the migration took 


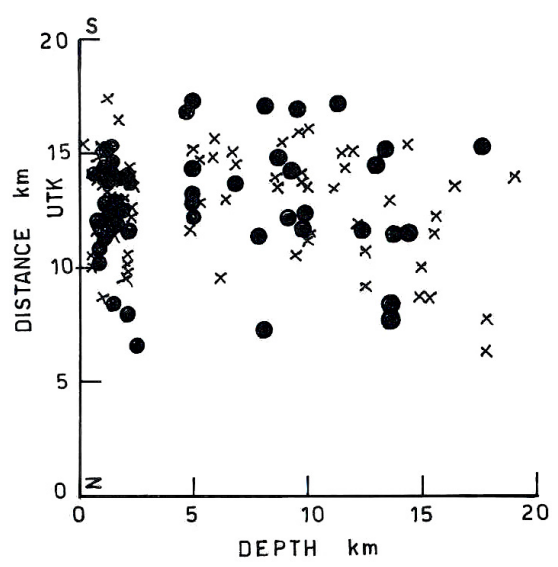

Fig. 4. Vertical cross section of 1995 (•) and 1996 (x) swarm activity along N-S traverses for three sets of events mentioned in Fig. 1. An increase in aperture of the 1996 swarm relative to the 1995 is observed

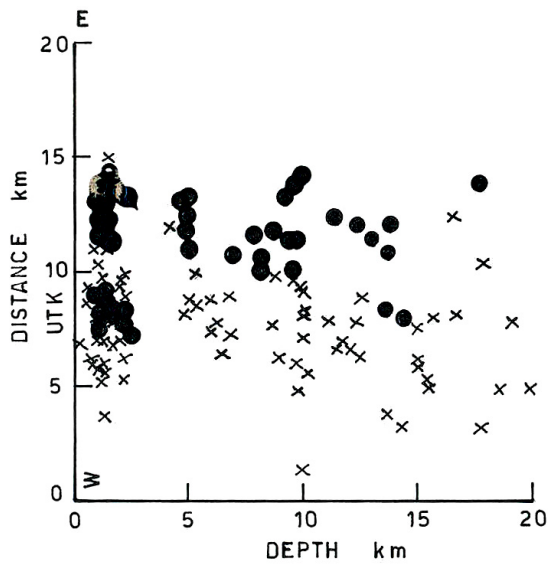

Fig. 5. Vertical cross section of $1995(\bullet)$ and 1996 (x) swarm activity along W-E traverses for three sets of events mentioned in Fig. 1. A westward migration and an increase in aperture of the 1996 swarm relative to the 1995 are observed

place from east to west, it is evidenced well in the east west (Fig. 5) than in the north-south cross section (Fig. 4). It is derived from the map that NNW elongated clusters have been formed. The occurrence of these swarms can be attributed to the activation of the Uttarkashi fault and other smaller lineaments adjoining Uttarkashi town (Fig. 1).

The lineaments present in this region are approximately parallel to the strike of the fault plane of 1991 Uttarkashi earthquake (Kayal 1996). The geometrical centers of these clusters fall in close proximity, with a lateral WSW migration of about $5-\mathrm{km}$. The similarity of the pattern as seen in Figs 3 and 5 suggests that both swarms originated form a single source of WSN migrating disturbance. Moreover, increase in the aperture towards west further indicates that the disturbance origi- 


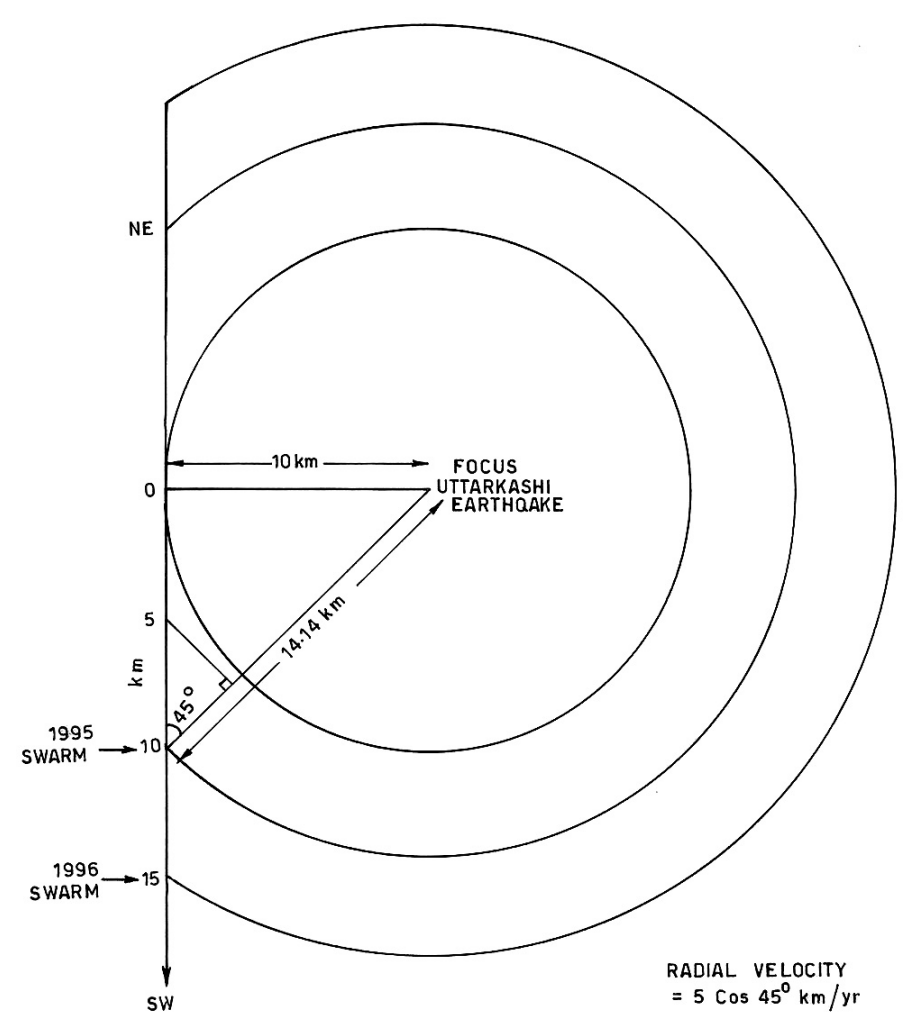

Fig. 6. SW-NE cross section of a homogeneous and isotropic earth model used to estimate the origin time of the disturbance causing the 1995 and 1996 swarms. A depth of $10 \mathrm{~km}$ is taken for the Uttarhashi Earthquake

nated and expanded from a source roughly towards east of these swarms. To mark the location of the source authors projected these clusters to a point by connecting their end points as shown in Fig. 1. The co-ordinates of the projected point along with the epicentral location of the Uttarkashi earthquake as given by National Geophysical Research Institute (NGRI), United State Geological Survey (USGS) and India Meoteological department (IMD) are shown in Table I. The co-ordinates of the projected points are closest (within $2.7 \mathrm{~min}$ in longitude and $1 \mathrm{~min}$ in latitude) to the epicenter given by NGRI. A recent study of the Uttarkashi earthquake seismic-sequence by Kayal (1996) shows that the epicentral location given by the NGRI is the most precise one. Thus, the projection center agrees very well with this location.

Figures 4 and 5 show an increase in the aperture width (aerial distance of events distribution) of about $2.5 \mathrm{~km}$ in $1996 \mathrm{swarm}$ relative to 1995 . Since, the stress distribution and change in aperture width along a cross section would be affected significantly by variations in the structure and material property with depth. Therefore, lateral migration of increase in depth of the swarm activity, would have been about $7.5 \mathrm{~km}$ during 1991. Also, the horizontal distance between these two swarms is 5 
Table I. Epicentral location of 1991 Uttarkashi earthquake: estimates from this study, and various organisations

\begin{tabular}{cccccc}
\hline $\begin{array}{c}\text { Present } \\
\text { study }\end{array}$ & $\begin{array}{c}\text { Latitude } \\
\text { (deg. min.) }\end{array}$ & $\begin{array}{c}\text { Longitude } \\
\text { (deg. min.) }\end{array}$ & Source & $\begin{array}{c}\text { Latitude } \\
(\text { deg. min. })\end{array}$ & $\begin{array}{c}\text { Longitude } \\
\text { (deg. min.) }\end{array}$ \\
\hline 88 events & 3045.50 & 7838.70 & NGRI & 3045.20 & 7836.00 \\
\hline 110 events & 3045.90 & 7838.60 & IMD & 3045.00 & 7851.60 \\
\hline 126 events & 3045.65 & 7838.67 & USGS & 3046.80 & 7846.20 \\
\hline
\end{tabular}

$\mathrm{km}$. Figure 6 suggests that the aperture varying (increasing) by $2.5 \mathrm{~km}$ per year. Therefore, one can calculate the time of the origin of the swarm as follows:

$$
\begin{aligned}
\text { Horizontal velocity of swarm migration } & =5 \mathrm{~km} / \mathrm{yr} \\
\text { and, radial velocity } & =5 \cos 45^{\circ} \mathrm{km} / \mathrm{yr} \\
\text { time of the origin of the swarm } & =\text { distance } / \text { radial velocity } \\
& =14.14 \mathrm{~km} / 5 \cos 45^{\circ} \mathrm{km} / \mathrm{yr} \\
& =4 \text { years. }
\end{aligned}
$$

Hence, the swarm would have been originated 4 years before 1995 swarm i.e. in 1991 (Uttarkashi earthquake). This calculated value is comparable to the focal depth of approximately $10 \mathrm{~km}$ (Khattri 1995, Kayal 1996) of Uttarkashi earthquake, thus it again supports the fact that the source of the disturbance causing the two swarms was at the focus of Uttarkashi earthquake.

The average migration rate of the activity is about $5 \mathrm{~km} / \mathrm{yr}$ towards west while the distance of the 1995 swarm to the Uttarkashi epicenter is approximately 10 $\mathrm{km}$. Taking a case of homogeneous and isotropic earth model and hence assuming a constant migration rate of the disturbance authors have estimated its origin time from the focus of the Uttarkashi earthquake (Fig. 4). For this analysis we use a value of $\sim 10 \mathrm{~km}$ for the depth of focus. Simple calculations show that the disturbance causing the 1995, 1996 swarms would have originated in about 1991, approximately at the time of occurrence of Uttarkashi earthquake. The above analysis confirms the association of 1995, 1996 swarms to Uttarkashi earthquake. The question, which now arises, is how to explain the delay of 4 years (from 1991 to 1995) leading to postseismic swarm activity.

\section{Swarm triggering process}

It may be mentioned that precursor earthquakes (Shanker et al. 2000) trigger these swarms. The triggering of seismic activity by large earthquake in adjoining region has recently been documented in literature (Stein et al. 1994, Nalbant et al. 1998, Harris 1998). It has been proposed that such delayed activity can takes place due to (i) static stress changes caused by the coseismic slip of the large event thus increasing the probability of future events in some regions, (ii) rate and state dependent friction allowing for delay in triggering of activity, (iii) due to post seismic 
creep (stable-slip) on causative fault altering the stress distribution or (iii) relaxation of a viscous layer beneath the brittle crust that leads to an increase in the stress change on nearby faults. All the above processes can explain the triggering and the delay in swarm's occurrence. In order to explain the migration effect of the two swarms and coseismic generation of causative disturbance from the focus of the Uttarkashi earthquake following model have been proposed:

\section{a) Creep (stable-slip) Model}

Kayal (1996) has attributed the observed roughly westward migration of foreshocks and aftershocks, which are up to $15 \mathrm{~km}$ deep, to rupture direction at depth. Moreover, it has been shown that aseismic creep control the occurrence of rupture process (Harris 1998, Stuart and Tullis 1995). Thus, it is this creep (stable-slip) motion which would have resulted in the Uttarkashi foreshock and aftershocks. This nearly westward creep motion aided by Uttarkashi event and continued even after the 1991 main shock. The occurrence of post seismic creep in the region aided and amplified by the main shock is also supported by the analysis of Kayal (1996). He infers that the mainshock activated the Uttarkashi fault to produce aftershocks. Hence, the entire region of about $40 \times 30 \mathrm{~km}$ marked as source zone of mainshock and aftershocks in Fig. 7 would have been vulnerable to creep motion. In fact, it has been observed that the MCT is a zone of shearing (Ni and Barazangi 1984, Seeber et al. 1981) thereby proving the occurrence of creep motion in the region. This creep motion emanated from the region of the mainshock and transferred stresses to the distant regions westward. The transmission of accumulated stresses on the basement thrust to Uttarkashi fault (Kayal 1996) resulting in 1991 event would have occurred due to similar creep phenomenon (Fig. 7). The NE-SW direction of the compressional stress (Fig. 1) is approximately transverse to the two swarms and the strike of the Himalaya. These evidences fit very well into the picture with westward creep and westward migration of the swarms. Analysis of levelling and sparse Global Positioning System (GPS) data in the Central Himalaya inferred the dominating occurrence of creep on the plate boundary fault below and north of the Higher Himalaya (Bilham et al. 1997, 1998). The moderate earthquake of Uttarkashi aided creep process to transfer stresses south of the Higher Himalayas this is accumulated with time at various distances from Uttarkashi earthquake focus. This stress accumulation resulted in 1995, 1996 swarms on two faults lying just on the border of foreshock and aftershock zone.

If one assumes that the focal depth of the Uttarkashi mainshock was greater than $10 \mathrm{~km}$, such as $12 \mathrm{~km}$ as suggested by IMD, the disturbance would have been at the focus about six months earlier than the main shock (by simple velocity-distance relation). If so, one may attribute this six months advance to creep, which also resulted in the Uttarkashi earthquake foreshocks. 


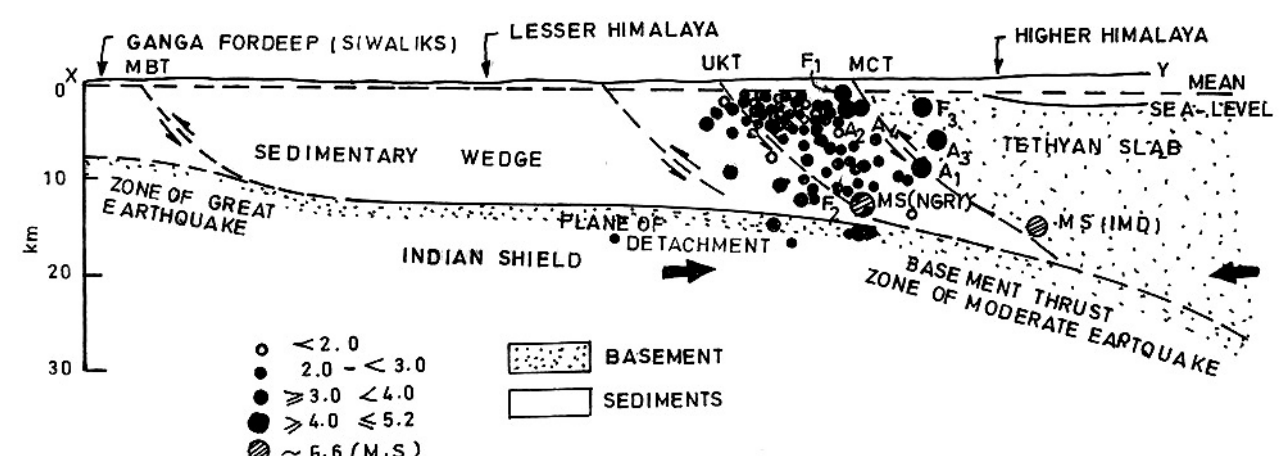

Fig. 7. Cross section along X-Y of Fig. 1, along with the hypocenters of events of Uttarkashi sequences (after Kayal 1996). The solid arrow indicates the relative movement of the plates. The plane of detachment and basement are envisaged by Seeber et al. (1981)

\section{b) Viscoelastic Loading Model}

For a depth of less than $10 \mathrm{~km}$ these disturbances would have originated later than the main shock. In this case the disturbance causing the swarms may have originated very soon (few months) after the Uttarkashi shock. For such possible situation a viscoelastic loading model is also likely to be valid. The loading of the region due to viscoelastic response of the lower crust or mantle could trigger seismic activity (Freed and Lin 1998, Shanker et al. 2000). Seismic observations and modeling studies have inferred the presence of a molten lower Tibetan crust (Owens and Zandt 1997). Moreover, region of the detachment on which earthquakes of moderate magnitude occur lie very close to the lower Tibetan crust, which could have responded to the Uttarkashi earthquake. Although in this model or any other model of static loading, explaining the migration effect of the two swarms is not straightforward. One of the possibilities could be that 1995 swarm triggered the 1996 activity. In view of absence of a clear process of migration and zero (or very small) time lag of the origin of the disturbance causing the two swarms we do not prefer this model.

A third possibility, in which migration of swarm activity (Uttarkashi earthquake triggered) is more apparent, could be the combination of the above two possibilities. That is, the postseismic creep (stable-slip) in Uttarkashi earthquake source zone could have been amplified by the viscoelastic response of lower Tibetan crust. As mentioned above, the stress transmission from Tibetan crust to Uttarkashi fault aided by creep on the basement thrust is possible.

Whether Uttarkashi earthquake has resulted in an increased seismicity on the MCT is not known because no recording stations were operating in the region during that period. Such an increase in seismic activity would have been governed by (i) activity of the MCT, (ii) direction of creep motion and (iii) the location of mainshock focus. A number of workers believe that MCT is now dormant structure (Le fort 1975, Ni and Barazangi 1984, Yin 1993) and the direction of the creep motion is towards west. Thus, it is expected that migration of stress concentration would also 
occur towards west (Toda et al. 1998). It is inferred from the above analysis that focus of the Uttarkashi earthquake lies to the south of the MCT (Kayal 1996) and it would have increased seismic activity on the MCT

\section{Summary and conclusion}

Continuous aseismic slip occurs on the basement thrust to the north of the Higher Himalayas. This motion results in strain accumulation on the southward locked portion of the basement thrust and above it. The occurrence of Uttarkashi earthquake, due to this motion, and further migrate the strain accumulation process towards south observed as earthquake triggered swarm migration. It seems from the above analysis that the seismic activity is migrating towards NW of Uttarkashi. The entire process results basically due to on going subduction of Indian plate. Thus, there is a strong evidence that the occurrence of 1991 Uttarkashi earthquake has triggered the 1995 and 1996 swarms in the Garhwal Himalayas. On the same analogy, it is likely that large earthquakes in the Himalayas may trigger seismic activity in nearby faults after delay of a few years and at distances of several kilometers from their origin. The migration of swarms is due to the migration of stress concentration along curved surface of fault (Fig. 6) and delay is due to the stable-slip (creep) motion.

Thus study contributes to the investigation of seismicity triggering by previous strong earthquake. Seismicity migration to nearby faults affects their proximity to failure, thus changing future earthquake probabilities. The proposed approach is very general and derived from the commonly accepted assumptions and constraints related to earthquake occurrence. This study would be useful for seismic hazard/risk assessment, in an area previously identified as a seismic gap. These aspects have to be taken into account in any future micro-seismic hazard zonation study in the region.

\section{Acknowledgements}

The first author is indebted to Prof. and Head of the Department of Earthquake Engineering, Indian Institute of Technology Roorkee (formerly University of Roorkee), Roorkee, India for providing necessary facilities to carry out the work. This research has been supported by All India Council for Technical Education (AICTE), New Delhi under the Research and Development Project Grant No. 8020/RID/R and D-129/01-02. 


\section{References}

Bilham R, Larson K, Freymulle J, project ldylmim members 1997: Nature, 386, 61-64.

Bilham R, Blume F, Bendick R, Gaur V K 1998: Curr. Sci., 74, 213-229.

Chander R, Sarkar I, Khattri K N, Gaur V K 1986: Tectonophysics, 124, 133-140.

Freed A M, Lin J 1998: J. Geophys. Res., 103, 24393-24409.

Harris R A 1998: J. Geophys. Res., 103, 24347-24358.

Kayal J P 1996: Tectonophysics, 263, 339-345.

Khattri K N 1995: Curr. Sci., 69, 161-171.

Khattri K N, Tyagi A K 1983: Tectonophysics, 96, 281-297.

Kumar A, Pandey A D, Sharma M L, Gupta S C, Jindal A K, Jain S K 1998: In: Proc. Eleventh Symp. On Earthquake Engg. Roorkee Univ., Dec. 17-19.

Le Fort P 1975: Am. J. Sci., 275-A, 1-44.

Nalbant S S, Hubert A, King G C P 1998: J. Geophys. Res., 103, 24469-24486.

Ni J, Barazangi M 1984: J. Geophys. Res., 89,1147-1163.

Owens T J, Zandt G 1997: Nature, 387, 37-42.

Seeber L, Armbruster J, Quittmeyer R 1981: Am. Geophys. Union, Geodyn. Ser., 3, 215-242.

Shanker D, Bhawani Singh, Singh V P 2000: Acta. Geoph. Geod. Hung., 35, 195-204.

Stein R S, King G C P, Lin 1994: Science, 265, 1432-1435.

Stuart W D, Tullis T E 1995: J. Geophys. Res., 100, 24097-24099.

Toda S, Stein R S, Reasenberg P A, Dieterich J H, Yoshida A 1998: J. Geophys. Res., 103, 24543-24565.

Wason H R, Jitendra Kumar, Walia S K 1994: Post Uttarkashi Earthquake seismic pattern in the Grahwal Himalaya region, Group meeting Seismotectonics and Geodynamics of Himalaya, Oct., Roorkee, India

Yin A 1993: J. Geophys. Res., 98, 14245-14256. 